\title{
Effect of temperature on the metabolism, behaviour and oxygen requirements of Sparus aurata
}

\author{
Mette Remen $^{1, *}$, Marit A. J. Nederlof ${ }^{2}$, Ole Folkedal ${ }^{1}$, Grethe Thorsheim ${ }^{1}$, \\ Ariadna Sitjà-Bobadilla ${ }^{3}$, Jaume Pérez-Sánchez ${ }^{3}$, Frode Oppedal ${ }^{1}$, Rolf Erik Olsen ${ }^{1,4}$ \\ ${ }^{1}$ Institute of Marine Research, 5984 Matredal, Norway \\ ${ }^{2}$ Department of Aquaculture and Fisheries, Wageningen University, De Elst 1, 6708 WD Wageningen, The Netherlands \\ ${ }^{3}$ Institute of Aquaculture Torre la Sal (IATS-CSIC), 12595 Ribera de Cabanes, Castellón, Spain \\ ${ }^{4}$ Present address: Norwegian University of Science and Technology, Department of Biology, 7491 Trondheim, Norway
}

\begin{abstract}
We investigated the effect of temperature on the limiting oxygen saturation (LOS) of gilthead sea bream Sparus aurata. This threshold was defined as the $\% \mathrm{O}_{2}$ saturation where fish no longer upheld their routine metabolic rate (RMR, the metabolic rate of fed and active fish) during a progressive decline in oxygen saturation. S. aurata $(398 \pm 10 \mathrm{~g}$, mean $\pm \mathrm{SE}$ ) were kept in 3 replicate tanks and subjected to 3 changes in temperature: 16 to $20^{\circ} \mathrm{C}, 20$ to $16^{\circ} \mathrm{C}$ and 16 to $12^{\circ} \mathrm{C}$. At each temperature, fish were left to acclimatize for 8 to $10 \mathrm{~d}$, before daily feed intake (DFI), the routine oxygen consumption rate (routine $\mathrm{MO}_{2}, \mathrm{mg} \mathrm{kg}^{-1} \mathrm{~min}^{-1}$ ) and the LOS were measured. In addition, at $20^{\circ} \mathrm{C}$ the swimming speed was measured in fish subjected to a decline in $\mathrm{O}_{2}$ from full air saturation to levels below the LOS (minimum of 8-10\% $\mathrm{O}_{2}$ ). For the temperature range tested $\left(12-20^{\circ} \mathrm{C}\right), \mathrm{DFI}, \mathrm{MO}_{2}$ and LOS increased exponentially with temperature (7.5-, 3.6- and 2.2-fold, respectively) with mean ( $\pm \mathrm{SE}$ ) LOS being $17 \pm 1,21 \pm 0$ and $35 \pm 5 \% \mathrm{O}_{2}$ at 12,16 and $20^{\circ} \mathrm{C}$, respectively. A gradual decline in swimming activity was observed as $\mathrm{O}_{2}$ declined below the LOS, indicating increasing metabolic stress and/or a 'sit-out' coping strategy which may prolong survival time in severe hypoxia. The results show the importance of temperature as an influential variable over the environmental $\mathrm{O}_{2}$ requirements of $S$. aurata.
\end{abstract}

KEY WORDS: Hypoxia $\cdot$ Aquaculture $\cdot$ Metabolism $\cdot$ Behaviour $\cdot \mathrm{P}_{\text {crit }} \cdot \mathrm{S}_{\text {crit }} \cdot$ Oxygen threshold $\cdot$ Feeding rate $\cdot$ Temperature

\section{INTRODUCTION}

Gilthead sea bream Sparus aurata is an important aquaculture species in countries surrounding the Mediterranean Sea, with 154000 t produced globally in 2011 (FAO 2013). The growth phase is primarily carried out in floating sea cages (Basurco et al. 2011) where fish performance and welfare are closely linked to environmental conditions within the sea cage (Fry 1971, Huntingford \& Kadri 2008). The sea cage oxygen $\left(\mathrm{O}_{2}\right)$ level is particularly important as it is the main limiting factor of fish aer-

${ }^{*}$ Corresponding author: mette.remen@gmail.com obic metabolism (Fry 1947, 1971). Studies in Atlantic salmon sea cages have revealed that $\mathrm{O}_{2}$ may drop to alarmingly low levels, at times down to $30 \% \mathrm{O}_{2}$. Factors contributing to these low $\mathrm{O}_{2}$ levels include water temperature, fish stocking density, algal density and water exchange rate (Crampton et al. 2003, Johansson et al. 2006, 2007, Oppedal et al. 2011). There is currently little information on the sea cage $\mathrm{O}_{2}$ levels in $S$. aurata aquaculture, but variation in the above mentioned factors is expected to cause variable levels of $\mathrm{O}_{2}$ in $S$. aurata production systems as well. In order to develop production strategies

(C) The authors 2015. Open Access under Creative Commons by Attribution Licence. Use, distribution and reproduction are unrestricted. Authors and original publication must be credited. 
that ensure proper physiological function and survival of the fish, it is important to define a limit for acceptable drops in $\mathrm{O}_{2}$.

When subjected to a gradual decline in $\mathrm{O}_{2}$, sparid species are able to uphold their oxygen consumption rate $\left(\mathrm{MO}_{2}\right)$ over a relatively wide range of $\mathrm{O}_{2}$ saturations (Cerezo \& García García 2004, Valverde et al. 2006). They do this mainly by increasing gill ventilation and perfusion (Perry et al. 2009). At a certain level of $\mathrm{O}_{2}$, regulatory mechanisms are no longer sufficient to uphold $\mathrm{MO}_{2}$ and it starts to decrease with further reductions in $\mathrm{O}_{2}$ (Pörtner \& Grieshaber 1993). This threshold is termed the critical oxygen saturation $\left(\mathrm{S}_{\text {crit }}\right.$ or $\mathrm{P}_{\text {crit }}$ if $\mathrm{O}_{2}$ is presented in units of gas pressure, when determined in resting, fasted fish at a known, stable temperature, i.e. in fish with standard metabolic rates (Schurmann \& Steffensen 1997, Claireaux \& Lagardère 1999, Behrens \& Steffensen 2007). However, when this threshold is determined in fed fish engaged in voluntary swimming activity, i.e. fish with routine metabolic rates (RMRs), this threshold has been termed the limiting oxygen saturation (LOS). The LOS departs from $\mathrm{S}_{\text {crit }}$ in being a continuum which correlates with RMR at a given temperature (e.g. Claireaux et al. 2000, Claireaux \& Lagardère 1999, Remen et al. 2013). The LOS may therefore change according to swimming speed (Steinhausen et al. 2010), specific dynamic action (SDA; the post-prandial increase in metabolism; reviewed by Secor 2009) or other factors that cause variation in RMR. In the present paper, the threshold $\mathrm{O}_{2}$ level below which $\mathrm{MO}_{2}$ decreases is presented as LOS, since it is determined in fed $S$. aurata engaged in voluntary swimming activity, and because units of oxygen saturation (\% of air saturation) are most commonly used by aquaculturists.

When $\mathrm{O}_{2}$ decreases below the LOS, the fish must increase their anaerobic metabolic rate to compensate for the decreasing ATP production (reviewed by Pörtner \& Grieshaber 1993). Anaerobic ATP production is far less efficient than aerobic ATP production, and the duration of survival becomes dependent on the availability of substrates for anaerobiosis (Richards 2009, 2011). Further, a drop in $\mathrm{O}_{2}$ to levels below the LOS can be expected to induce stress (increased plasma levels of corticosteroids and catecholamines) and lactic acidosis (Van Raaij et al. 1996, Vianen et al. 2001, Petersen \& Gamperl 2011, Remen et al. 2012, 2013). The LOS can therefore be implemented in aquaculture as the lower limit for acceptable $\mathrm{O}_{2}$ levels with regard to the physiological function and welfare of farmed fish (Huntingford \& Kadri 2008).
The LOS is expected to increase with any factor that increases the aerobic metabolic rate (Fry 1971, Neill et al. 1994). One of the main factors influencing metabolic rate is temperature (Fry 1947, 1971), which is closely correlated with LOS and $\mathrm{S}_{\text {crit }}$ (e.g. Schurmann \& Steffensen 1997, Claireaux \& Lagardère 1999, Barnes et al. 2011, Richards 2011, Mamun et al. 2013, Remen et al. 2013). In order to develop an applicable oxygen threshold for the $S$. aurata industry, it is therefore necessary to investigate the relationship between temperature and LOS for this species. Further, it is important to do so under conditions as similar to production conditions as possible (fed, undisturbed and swimming fish in groups), as RMR, and thus the LOS, can be expected to vary considerably, e.g. with meal size (e.g. Guinea \& Fernandez 1997) and swimming speed (e.g. Steinhausen et al. 2010) at a given temperature.

The main aim of this study was to determine the relationship between temperature $\left(12-20^{\circ} \mathrm{C}\right)$ and LOS for $S$. aurata. To mimic an aquaculture setting, LOS was determined in fed and undisturbed fish. Further, swimming speed and behaviour of $S$. aurata at $\mathrm{O}_{2}$ declining from full saturation to levels below the LOS were investigated in order to study the behavioural response of this species to a progressive drop in $\mathrm{O}_{2}$.

\section{MATERIALS AND METHODS}

All experimental work was conducted in accordance with the laws and regulations for experiments and procedures on live animals in Norway, following the Norwegian Regulation on Animal Experimentation 1996. The experiment was approved by Forsøksdyrutvalget (FOTS ID 4580).

\section{Fish material and experimental facilities}

Sparus aurata juveniles (5 g) were purchased from Ferme Marine de Douhet hatchery, Ile d'Oléron, France, and transported to the Institute of Aquaculture Torre de la Sal in Spain in July 2011. Fish were fed to satiety (EFICO YM 554, BioMar) and kept in an open flow system (salinity $37.5 \mathrm{ppt}$ ) with natural photoperiod and water temperature until they reached $150 \mathrm{~g}$. They were then transported to Matre Research Station, Institute of Marine Research in Norway in January 2012. No fish died during transport. On arrival, a total of 99 fish were distributed into three 5001 squared flow-through experimental tanks with 
lids fitted with $18 \mathrm{~W}$ fluorescent light tubes and automatic feeders (Arvo-Tec T drum 2000, www.arvotec.fi). Feed was provided twice daily during the entire experiment (Amber Neptun 100, 5 mm, Skretting, Norway), aiming for $>30 \%$ overfeeding. Spill feed was weighed, and feed intake was estimated according to the method of Helland et al. (1996). Calculations for estimation of the tank biomass over time are shown in 'Calculations and statistics' below. Fish were kept on a 12:12 h light:dark h cycle at $34 \mathrm{ppt}$, $16^{\circ} \mathrm{C}$ and $\mathrm{O}_{2}$ saturation $>80 \%$ until fish reached a size of $397 \pm 10 \mathrm{~g}$ (mean $\pm \mathrm{SE}$ ) at the start of the experiment on 13 July 2012 (Table 1).

Temperature and oxygen were continuously monitored using Oxyguard 420 probes mounted inside the tanks (accuracy of $\pm 0.2 \% \mathrm{O}_{2}$, Oxyguard International), and logged every $31 \mathrm{~s}$ using the Commander software (OxyGuard). In each tank, a camera (VNSVUC-MINI, Seavision, SubSea) was attached to the tank wall approx. $20 \mathrm{~cm}$ below the water surface, directed outwards into the tank. Daily inspections of the tanks and recordings of fish behaviour were managed using Hikvision capture card and DVRserver V6.67 software (Hikvision).

\section{Experimental set-up}

All fish were anaesthetized (MS-222, $150 \mathrm{mg} \mathrm{l}^{-1}$, Fluca Analytical, Sigma-Aldrich), weighed (to the nearest $\mathrm{g}$ ) and measured ( $\mathrm{cm}$ fork length) at the start of the experimental period (Day 0, Table 1). During the experimental period, fish in all 3 tanks were subjected to 3 changes in temperature: 16 to $20^{\circ} \mathrm{C}$ (Days 1-2), 20 to $16^{\circ} \mathrm{C}$ (Days 12-13) and 16 to $12^{\circ} \mathrm{C}$ (Days 20-21). This regime was chosen in order to minimize the change in temperature at each temperature adjustment, and the temperature range

Table 1. Overall mean ( \pm SE) gilthead sea bream Sparus aurata weights $(W, g)$, lengths $(L, \mathrm{~cm}$ fork length), condition factor $\left(K\right.$, calculated as $\left.100 \mathrm{~W} / \mathrm{L}^{3}\right)$ and total number of fish (N) in the 3 replicate tanks at the start of the experiment (Day 0), on Day 28 and on Day 45. Two fish from 1 of the replicate tanks were taken out on Day 28 due to their low weights (approximately $100 \mathrm{~g}$ ), and 5 fish from each tank were taken during blood sampling on Day 35

\begin{tabular}{|llccc|}
\hline Day & $W(\mathrm{~g})$ & $L(\mathrm{~cm})$ & $K$ & $\mathrm{~N}$ \\
\hline 0 & $397 \pm 10$ & $25.0 \pm 0.2$ & $2.3 \pm 0.0$ & 82 \\
28 & $421 \pm 15$ & $26.4 \pm 0.2$ & $2.3 \pm 0.0$ & 82 \\
45 & $485 \pm 8$ & $27.2 \pm 0.2$ & $2.3 \pm 0.0$ & 65 \\
\hline
\end{tabular}

$\left(12-20^{\circ} \mathrm{C}\right)$ was used because $12^{\circ} \mathrm{C}$ is a minimum temperature for growth (Mingarro et al. 2002, Hernández et al. 2003) and because $20^{\circ} \mathrm{C}$ was the maximum temperature possible in the laboratory. The change in temperature was changed in a stepwise manner at a rate of $2^{\circ} \mathrm{C} \mathrm{d}^{-1}$. At each new temperature $(20,16$, $12^{\circ} \mathrm{C}$ ) the fish were left to acclimatize for 8 to $10 \mathrm{~d}$ before measurements of $\mathrm{MO}_{2}$ and LOS (Days 12, 20 and 28, respectively). After the final LOS measurement on Day 28, all fish were anaesthetized (MS-222, $150 \mathrm{mg} \mathrm{l}^{-1}$ ) and weights and lengths measured. They were then returned to the tanks and kept for another $12 \mathrm{~d}$ at $20^{\circ} \mathrm{C}$ before the final study of swimming speed during a decline in $\mathrm{O}_{2}$ at $20^{\circ} \mathrm{C}$. This temperature was chosen because the activity level in terms of feeding was highest (see below for details on swimming speed measurements). After this, anaesthetized fish were killed by a blow to the head and the weights and lengths of all fish were recorded (Table 1).

\section{Measurements of routine $\mathrm{MO}_{2}$ and LOS}

The tank water level was recorded $1 \mathrm{~d}$ before measurements started. Fish were fed as usual in the morning, and $\mathrm{MO}_{2}$ measurements were initiated $1.5 \mathrm{~h}$ later in order to achieve a measure of routine $\mathrm{MO}_{2}$. The water $\mathrm{O}_{2}$ level within the tank was raised to $120-140 \% \quad \mathrm{O}_{2}$ by adding oxygen-supersaturated water $\left(\sim 400 \% \mathrm{O}_{2}\right)$, the flow in and out of the tanks was stopped, and the $\mathrm{O}_{2}$ level was allowed to decline as a result of fish respiring within the tank. This continued until the rate of $\mathrm{O}_{2}$ decline was visibly lowered, suggesting that the $\mathrm{MO}_{2}$ of the fish was depressed and the LOS had been surpassed (a more accurate estimation of LOS was performed later on, see below). The duration of this period ranged from $2 \mathrm{~h}$ at $20^{\circ} \mathrm{C}$ to $5 \mathrm{~h}$ at $12^{\circ} \mathrm{C}$, and $\mathrm{O}_{2}$ saturation was between 7 and $10 \%$ at the end. Water in- and outflow was then restored. During the period with no water exchange, there is an inevitable build-up of wastes $\left(\mathrm{CO}_{2}\right.$, ammonia etc.), which occurs at a rate that corresponds to the $\mathrm{MO}_{2}$ of the fish. As this is also the case in an aquaculture situation where a drop in $\mathrm{O}_{2}$ is caused by fish/algae/bacteria consumption, no attempt was made to correct for a possible effect of such wastes on fish $\mathrm{MO}_{2}$.

The oxygen influx over the water surface during the progressive decline in oxygen was examined by measuring the $\mathrm{O}_{2}$ change over time in a tank without fish with $16^{\circ} \mathrm{C}$ seawater that had been oxygenstripped using $\mathrm{N}_{2}$ gas $\left(\mathrm{O}_{2} ; 11 \%\right.$ of air saturation). In a similar situation to the experiment, there was no 
water entering or leaving the tank, and the circulation of water caused by fish movements was mimicked using a recirculation pump connected to the inlet (EHEIM Universal pump 1250, $201 \mathrm{~min}^{-1}$ ). The influx of $\mathrm{O}_{2}$ to the water volume through diffusion $\left(\mathrm{O}_{2}\right.$ influx, $\left.\mathrm{mg} \mathrm{O}_{2} \mathrm{l}^{-1} \mathrm{~min}^{-1}\right)$ was modelled as:

$$
\mathrm{O}_{2} \text { influx }=k\left(\alpha-C_{t}\right)
$$

where $k$ is the diffusion constant, $\alpha$ is oxygen solubility $\left(\mathrm{mg} \mathrm{l}^{-1}\right)$ at the prevailing temperature and salinity, and $C_{t}$ is the oxygen concentration ( $\mathrm{mg} \mathrm{l}^{-1}$ ) within the tank at time $t$. The diffusion constant, $k$, was estimated to be 0.0013275 , by finding the value of $k$ that maximized the correlation between the observed and modelled increase in oxygen saturation after oxygenstripping $\left(\mathrm{R}^{2}=0.99\right)$. It should be noted that the $\mathrm{O}_{2}$ influx depends on the circulation of water within the tank. With no circulation, the contribution of $\mathrm{O}_{2}$ influx on the change in tank $C_{t}$ was negligible, but a significant contribution was found when introducing the recirculation pump. The pump created a circulation considered to be noticeably higher than what can be achieved by a group of fish swimming in the tank (water current speed ranging between 7 and $23 \mathrm{~cm} \mathrm{~s}^{-1}$ depending on the distance from the tank centre), and the real value of $k$ can therefore be expected to be somewhere in the range of 0 to 0.0013275 . The estimated LOS did not change as a result of $k$ varying in the range of 0 to 0.0013275 , but $\mathrm{MO}_{2}$ did. The effect of $k$ on $\mathrm{MO}_{2}$ increased with the duration of no inflow (from $2 \mathrm{~h}$ at $20^{\circ} \mathrm{C}$ to $5 \mathrm{~h}$ at $12^{\circ} \mathrm{C}$ ), resulting in an increase in normoxic $\mathrm{MO}_{2}$ $\left(\mathrm{O}_{2}\right.$ between LOS and $\left.100 \% \mathrm{O}_{2}\right)$ equivalent of $4 \pm 1$, $10 \pm 1$ and $18 \pm 1 \%$ at 20,16 and $12^{\circ} \mathrm{C}$, respectively, using a $k=0.0013275$ compared to using a $k=0$. This corresponds to an absolute change in $\mathrm{MO}_{2}$ equivalent to $0.15-0.18 \mathrm{mg} \mathrm{O}_{2} \mathrm{~kg}^{-1} \mathrm{~min}^{-1}$, a possible overestimation that was considered within acceptable limits for a measure of routine $\mathrm{MO}_{2}$. The routine $\mathrm{MO}_{2}(\mathrm{mg}$ $\mathrm{O}_{2} \mathrm{~kg}^{-1} \mathrm{~min}^{-1}$ ) was calculated as

$$
\mathrm{MO}_{2}=V\left(C_{t-1}-C_{t}+\mathrm{O}_{2} \text { influx }\right) / \mathrm{BM}
$$

where $V$ is the tank volume $(\sim 4601), C_{t}$ is the oxygen concentration $\left(\mathrm{mg} \mathrm{l}^{-1}\right)$ at time $t, C_{t-1}$ is the oxygen saturation 1 min earlier, and BM is the biomass $(\mathrm{kg})$.

In order to find the LOS and the normoxic $\mathrm{MO}_{2}$, $5 \min \left(20^{\circ} \mathrm{C}\right)$ or $10 \mathrm{~min}\left(12\right.$ and $\left.16^{\circ} \mathrm{C}\right)$ averages of $\mathrm{MO}_{2}$ were plotted against the average $\mathrm{O}_{2}$ saturations measured during the time intervals. A broken-line regression model was fitted to the data, and the curve break-point, representing the LOS, was established using the 'segmented' package in R 2.14.0 (The R Foundation for Statistical Computing @ 2011, www.r-project.org). This method simultaneously estimates slope parameters and the turning point(s) within a standard linear model framework (Muggeo 2008). Only $\mathrm{MO}_{2}$ values for $\mathrm{O}_{2} \leq 100 \%$ of air saturation were used, and the normoxic $\mathrm{MO}_{2}$ was determined by averaging $\mathrm{MO}_{2}$ at $\mathrm{O}_{2}$ above the LOS. A Davies test was used to test for a difference in slopes, and break-points were considered valid when the $\mathrm{p}$ value returned by the test was $\leq 0.05$ (Muggeo 2008).

\section{Swimming speed measurement}

During the decline in $\mathrm{O}_{2}$ at $20^{\circ} \mathrm{C}$ (Day 45), swimming speeds were recorded every 10 min using cameras submerged halfway in the water column and placed in 1 corner of the tank, pointing towards the opposite corner of the squared, $500 \mathrm{l}$ tank. The inlet pipe in the opposite corner was used as a reference point for measuring the swimming speed (body lengths per second, BL s${ }^{-1}$; Fig. 1). This was done by measuring the time it took for a fish to pass the pipe (snout to tailfin), and was recorded for 10 fish at the start of every $10 \mathrm{~min}$ period during the decline in $\mathrm{O}_{2}$ (down to $8-10 \% \mathrm{O}_{2}$ ). Only fish swimming close to the pipe were chosen in order to avoid an effect of the distance between the camera and the fish. All measurements were performed within the first $2 \mathrm{~min}$ of the $10 \mathrm{~min}$ period. The swimming speed mea-

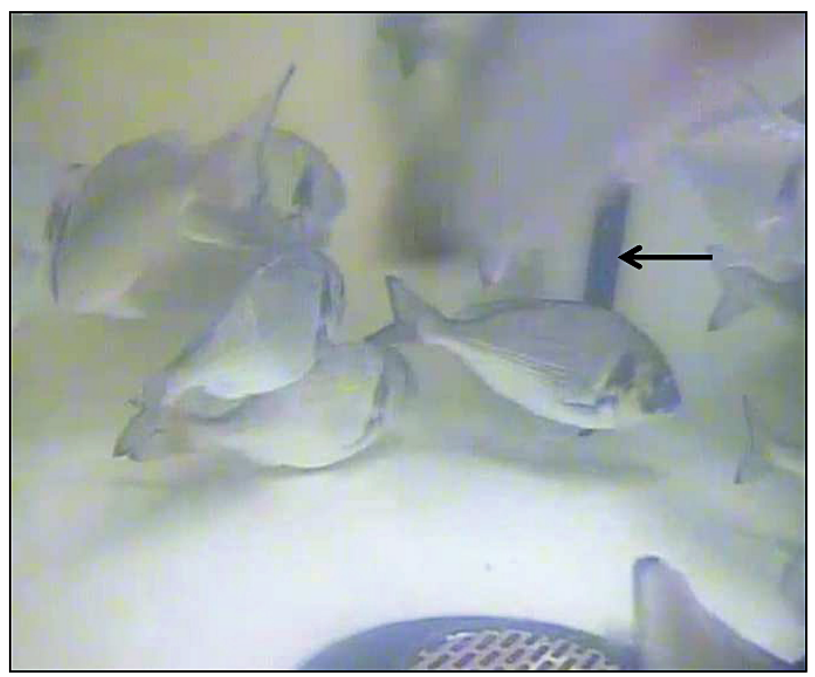

Fig. 1. Measurements of gilthead sea bream Sparus aurata swimming speed during declining $\mathrm{O}_{2}$ were performed by analysing videos from cameras submerged in the tanks. The time it took for a fish to pass (snout to tail fin) the right side of the inlet pipe (arrow) was noted and swimming speed was recalculated to body lengths per second 

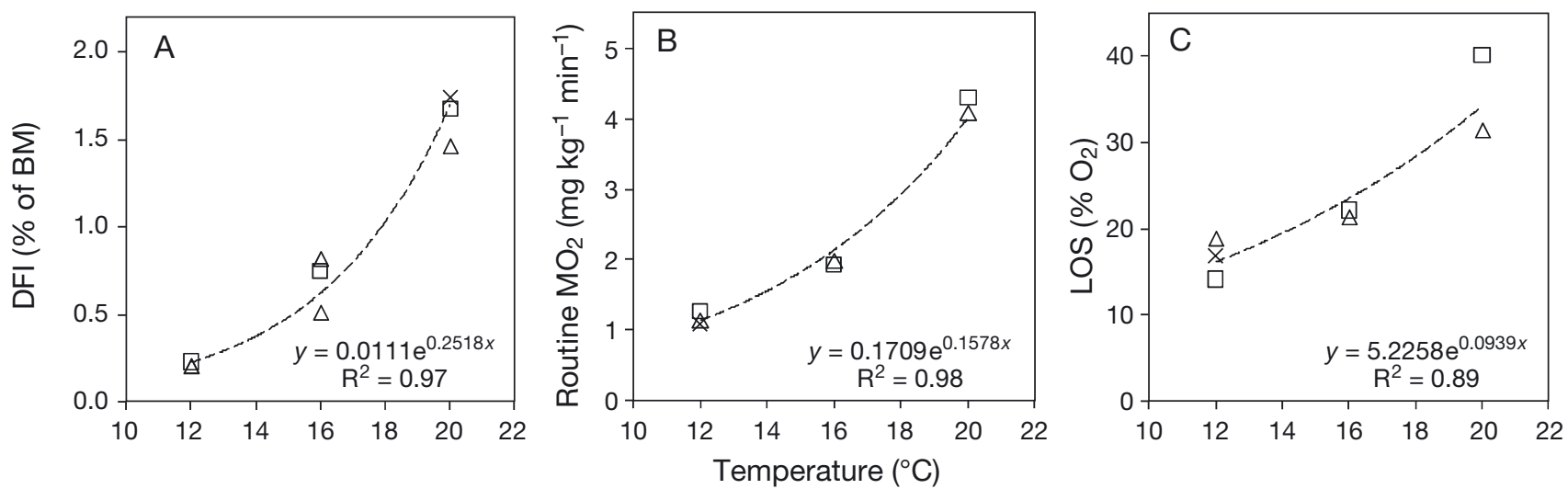

Fig. 2. Relationship between temperature and (A) the daily feed intake (DFI, \% of biomass, BM, measured on the day before limiting oxygen saturation, LOS, measurement), (B) the routine oxygen consumption rate (routine $\mathrm{MO}_{2}, \mathrm{mg} \mathrm{O}_{2} \mathrm{~kg}^{-1} \mathrm{~min}^{-1}$ ) and (C) the LOS (\% of air saturation) in 3 replicate tanks with groups of undisturbed, fed and freely swimming adult gilthead sea bream Sparus aurata. Each replicate tank is given a separate symbol in the graphs (note that one replicate is missing for $\mathrm{MO}_{2}$ and LOS measurements at 16 and $20^{\circ} \mathrm{C}$ ). Measurements at 20,16 and $12^{\circ} \mathrm{C}$ were performed on Days 12,20 and 28 , respectively, after $8 \mathrm{~d}$ of temperature acclimation. In all panels, exponential trend lines are fitted to the data, and the resulting equations are shown

surement was performed in 2 tanks only, as water leakage in the third tank led to reduced tank water level.

\section{Calculations and statistics}

The feed conversion ratio (FCR) was calculated as:

$$
\mathrm{FCR}=\mathrm{FI} /\left(\mathrm{BM}_{\mathrm{end}}-\mathrm{BM}_{\text {start }}\right)
$$

where FI represents the total feed intake ( $g$ ) during the period in question, $\mathrm{BM}_{\text {end }}$ is the biomass $(\mathrm{g})$ at the end of this period, and $\mathrm{BM}_{\text {start }}$ is the biomass $(\mathrm{g})$ at the start of the period. The total feed intake and the tank biomass measured on Days 0, 28 and 45 were used to calculate FCR for Days 0 to 28 and Days 29 to 45.

Daily feed intake (DFI, \% of BM) was calculated according to the method described by Helland et al. (1996). The daily biomass, $\mathrm{BM}_{\text {day } n}(\mathrm{~g})$, was approximated using the FCR and the DFI ( $g$ ) according to the following formula:

$$
\mathrm{BM}_{\text {day } n}=\left(\mathrm{BM}_{\text {day } n-1}+\mathrm{DFI}_{\text {day } n-1}\right) / \mathrm{FCR}
$$

R (2.14.0 The R Foundation for Statistical Computing (C) 2011) was used to test for a difference in slopes (Davies test), for the 2 lines representing $\mathrm{MO}_{2}$ at $\mathrm{O}_{2}$ above and below the LOS (Muggeo 2008). All further statistical tests were performed using Statistica(C) (StatSoft). Fixed non-linear regression $\left(y=a \mathrm{e}^{b x}\right)$ was used to test the non-linear relationships between temperature and the parameters DFI, $\mathrm{MO}_{2}$ and LOS. A significance level of $5 \%$ was used for all tests.

\section{RESULTS}

\section{Effect of temperature on DFI, routine $\mathrm{MO}_{2}$ and LOS}

DFI and routine $\mathrm{MO}_{2}$ increased exponentially with temperature (fixed non-linear regression, $\mathrm{p}<0.02$, $\mathrm{R}^{2}>0.97$, Fig. 2A,B). Mean DFI $( \pm \mathrm{SE})$ was $0.22 \pm$ $0.01,0.70 \pm 0.09$ and $1.63 \pm 0.08 \%$ of $\mathrm{BM}$, and the mean routine $\mathrm{MO}_{2}$ was $1.2 \pm 0.1,1.6 \pm 0.4$ and $3.4 \pm$ $0.8 \mathrm{mg} \mathrm{O}_{2} \mathrm{~kg}^{-1} \mathrm{~min}^{-1}$ at 12,16 and $20^{\circ} \mathrm{C}$, respectively.

Broken-line regression models were significant for all plots of routine $\mathrm{MO}_{2}$ against ambient $\mathrm{O}_{2}$ for the 3 temperatures tested (Davies test, $\mathrm{p}<0.001, \mathrm{R}^{2}>$ 0.93). LOS increased exponentially with temperature (fixed non-linear regression, $\mathrm{p}<0.01, \mathrm{R}^{2}=0.89$ ), being $17 \pm 1,22 \pm 0$ and $36 \pm 4 \% \mathrm{O}_{2}$ at 12,16 and $20^{\circ} \mathrm{C}$, respectively (Fig. $2 \mathrm{C}$ ). One replicate is missing from both 16 and $20^{\circ} \mathrm{C}$ measurements, due to a small water leak from the tank during measurements.

\section{Behaviour during declining $\mathrm{O}_{2}$}

The swimming speed of Sparus aurata during a progressive decline in $\mathrm{O}_{2}$ at $20^{\circ} \mathrm{C}$ is shown in Fig. 3A, B. There was no change in swimming speed during the period of time when ambient $\mathrm{O}_{2}$ dropped towards the LOS. However, a steady decline in swimming speed was observed as $\mathrm{O}_{2}$ continued to decline below this threshold. No fish rested on the tank bottom, tried to escape, performed air-surface respiration or lost equilibrium during the decline in $\mathrm{O}_{2}$ to levels below 


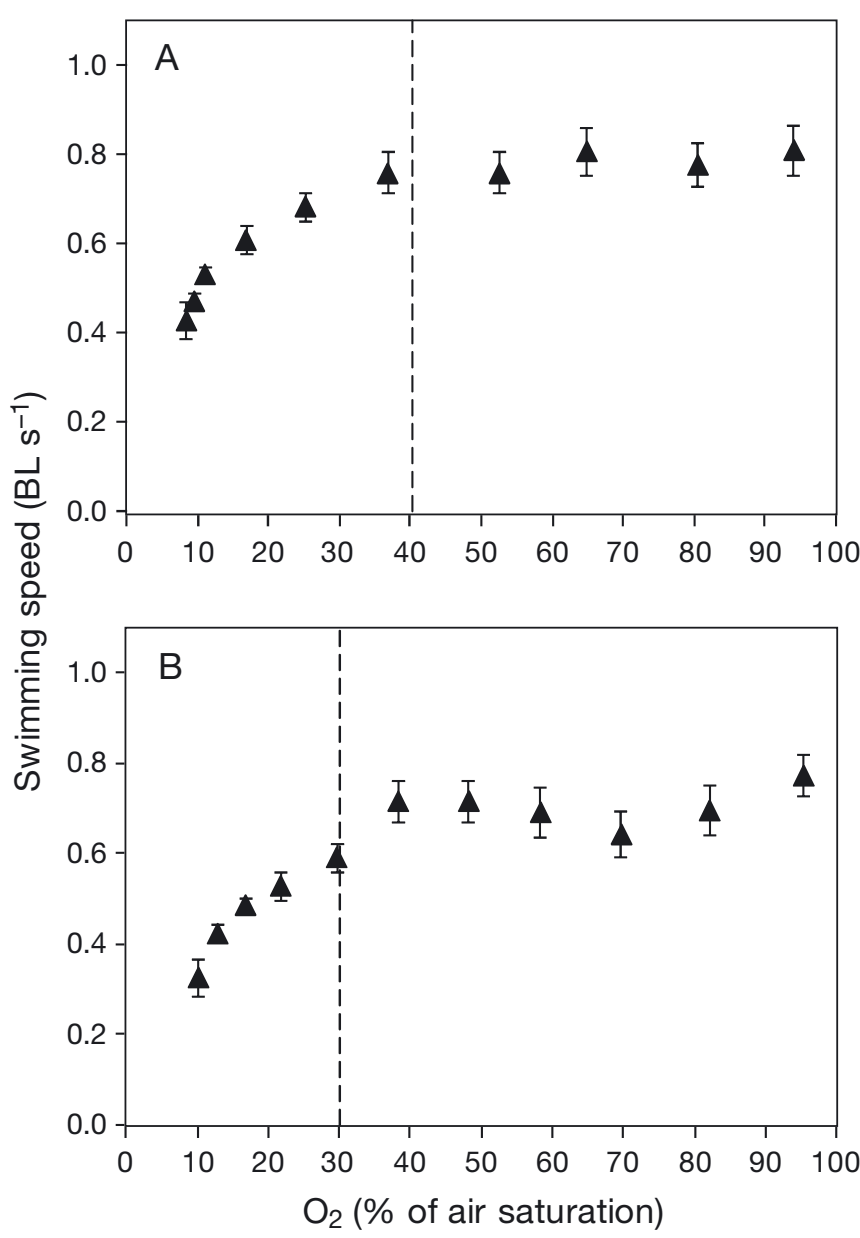

Fig. 3. Mean ( $\pm \mathrm{SE}, \mathrm{n}=10$ ) swimming speeds (body lengths, $\mathrm{BL}, \mathrm{s}^{-1}$ ) of gilthead sea bream Sparus aurata during a progressive decline in $\mathrm{O}_{2}$ in 2 replicate tanks (A and B) at $20^{\circ} \mathrm{C}$. The limiting oxygen saturation levels found for these 2 replicate tanks are represented as vertical broken lines. Swimming speed was measured every 10 min during the decline in $\mathrm{O}_{2}$

the LOS. Furthermore, the fish did not show any startle response when the tank lid was lifted after the end of the trial, compared to overt responses during normoxic conditions.

\section{DISCUSSION}

This study is the first to present the relationship between temperature $\left(12-20^{\circ} \mathrm{C}\right)$ and the RMR of Sparus aurata around harvest size $(\sim 400 \mathrm{~g})$, and the resulting increase in the minimum $\mathrm{O}_{2}$ required to uphold their RMR (the LOS; $17-36 \% \mathrm{O}_{2}$ ). When $\mathrm{O}_{2}$ declined below the LOS, the swimming speed of the fish started to decrease.

\section{Effect of temperature on RMR and LOS}

As expected, $\mathrm{MO}_{2}$ increased with temperature (Guinea \& Fernandez 1997, Ibarz et al. 2003, Libralato \& Solidoro 2008). As temperature increases, biochemical reactions proceed faster (Angilletta et al. 2002), and the metabolic cost of maintenance increases (Fry 1947, 1971). The capacity for feeding and growth increases with temperature until the thermal optimum is reached, and decreases thereafter (reviewed by Fry 1947, 1971, Farrell 2009, Pörtner 2010). The low feed intake and RMR observed at $12^{\circ} \mathrm{C}$ is in line with suggestions by Ibarz et al. (2003) that this temperature represents a lower limit for suitable temperatures in $S$. aurata aquaculture. The highest temperature used in the present study $\left(20^{\circ} \mathrm{C}\right)$ can be expected to be close to the optimal temperature for growth. Although higher temperatures of $24-26^{\circ} \mathrm{C}$ were found to maximize growth in the $S$. aurata growth model presented by Hernández et al. (2003), the same range $\left(24-26^{\circ} \mathrm{C}\right)$ was considered lethal by Feidantsis et al. (2009). Temperatures up to $26^{\circ} \mathrm{C}$ may occur in the surface water of the Mediterranean during summer (Damianidis \& Chintiroglou 2000), and further studies are therefore warranted in order to determine the relationship between temperature, RMR and LOS for the entire temperature range relevant for $S$. aurata aquaculture.

In line with previous observations, we found that the increase in RMR with temperature led to an elevation of the LOS (Schurmann \& Steffensen 1997, Claireaux \& Lagardère 1999, Valverde et al. 2006, Barnes et al. 2011, Richards 2011, Svendsen et al. 2012, Mamun et al. 2013, Remen et al. 2013). This confirms that temperature is an important factor to consider when determining oxygen thresholds. The LOS can be expected to increase with any factor that influences the aerobic metabolic rate of a fish (Fry 1971, Neill et al. 1994), and since the level of RMR is highly dependent on the feeding status of the fish (Guinea \& Fernández 1997), both temperature and feed intake are likely to have influenced the LOS (Thuy et al. 2010). The contribution of SDA to the value of RMR, and thus the LOS, in the present study is not clear, since none of these parameters were measured in fasted fish. It may, however, be considered small at $12^{\circ} \mathrm{C}$, due to the low feed intake (DFI = $0.21 \%$ of $\mathrm{BM})$, and considerable at $20^{\circ} \mathrm{C}$ (DFI $=$ $1.67 \%$ of BM). For the practical use of LOS in aquaculture, it is important to point out that LOS may be lower in fasted fish, particularly at the upper end of the temperature range tested. 


\section{Practical use of LOS as a limit for unacceptable drops in $\mathrm{O}_{2}$}

The LOS measured in the present study represents a minimum level of $\mathrm{O}_{2}$ required to uphold RMR, maintain physiological integrity and ensure survival (Neill et al. 1994). No fish died during or after the $1 \mathrm{~h}$ progressive drop in $\mathrm{O}_{2}$ below LOS in our study, suggesting that such a short-term exposure to $\mathrm{O}_{2}$ levels below this threshold is not a threat to survival. It may be expected that survival is threatened during longer exposure, as a result of the rapid consumption of fuels, and the accumulation of anaerobic end-products (reviewed by Richards 2009, 2011). Further, a drop in $\mathrm{O}_{2}$ below the LOS is expected to represent a stressor for the fish, resulting in elevated production of stress hormones (Van Raaij et al. 1996, Vianen et al. 2001, Petersen \& Gamperl 2011, Remen et al. 2012, 2013). Unpublished results from the present study confirm that plasma lactate and cortisol increased in $S$. aurata after a progressive drop in $\mathrm{O}_{2}$, declining below the LOS for the last hour. It is therefore suggested that LOS is a suitable limit for acceptable drops in $\mathrm{O}_{2}$ in $S$. aurata aquaculture, with respect to the physiological integrity and welfare of the fish (Huntingford \& Kadri 2008). It should be emphasized that higher levels of $\mathrm{O}_{2}$ are expected to obtain fast growth and efficient production, as appetite is generally reduced at higher levels of $\mathrm{O}_{2}$ than the LOS. For example, the appetite of post-smolt Atlantic salmon was found to be reduced at $70 \% \mathrm{O}_{2}$ at $16^{\circ} \mathrm{C}$, while the LOS was found to be $\sim 52 \% \mathrm{O}_{2}$ at the same temperature (Remen et al. 2012, 2013). In a general recommendation on suitable $\mathrm{O}_{2}$ levels in sparid aquaculture, $80-85 \% \mathrm{O}_{2}$ was suggested as a minimum for proper feeding and growth (Mozes et al. 2011), but further studies are required in order to confirm this recommendation and to determine the possible effect of temperature on the $\mathrm{O}_{2}$ required for maximal feeding and growth.

\section{Effect of $\mathrm{O}_{2}$ on swimming speed}

The swimming activity of $S$. aurata gradually decreased as the $\mathrm{O}_{2}$ level declined below the LOS, and no signs of agitation were observed. According to the species and the context, hypoxia may result in increased swimming activity (attempt to flee), a reduction ('sit out') in swimming activity (reviewed by Chapman \& McKenzie 2009) or no change (Metcalfe \& Butler 1984, van Raaij et al. 1996). The response of $S$. aurata to a progressive decline in $\mathrm{O}_{2}$ suggests that this species copes with hypoxia by reducing its activity level, a response that may conserve energy and prolong survival time when hypoxia cannot be avoided (reviewed by Chapman \& McKenzie 2009). A similar response has been seen in crucian carp Carassius carassius, eelpout Zoarces viviparus, white sturgeon Acipenser transmontanus and common sole Solea solea (Fischer et al. 1992, Nilsson et al. 1993, Dalla Via et al. 1998, Cech \& Crocker 2002). In species such as Atlantic herring Clupea harengus, rainbow trout Oncorhynchus mykiss and red hake Urophycis chuss (Bejda et al. 1987, van Raaij et al. 1996, Domenici et al. 2000), attempts to flee from the situation seem to be more prevalent. However, since the reduction of swimming speed was only observed at $\mathrm{O}_{2}$ below the LOS, it cannot be excluded that the reduction in swimming speed was a direct consequence of the increasing energy deficit experienced at these levels of $\mathrm{O}_{2}$. Further experiments are therefore required to identify whether the observed lack of response to visual stimuli in swimming fish after $1 \mathrm{~h}$ below LOS is a 'sit-out' strategy or a sign of pronounced energy deficit and severe metabolic stress.

\section{Conclusion and future perspectives}

We investigated the effect of temperature $\left(12-20^{\circ} \mathrm{C}\right)$ on feed intake and the RMR of $S$. aurata kept under conditions mimicking an aquaculture setting, and the resulting change in LOS. All measured parameters increased exponentially within the temperature range tested, with LOS being $17 \% \mathrm{O}_{2}$ at $12^{\circ} \mathrm{C}$ and $36 \% \mathrm{O}_{2}$ at $20^{\circ} \mathrm{C}$. The LOS can be implemented in aquaculture as a lower limit for acceptable drops in $\mathrm{O}_{2}$ with respect to physiological function and welfare of farmed $S$. aurata. Higher levels of $\mathrm{O}_{2}$ are required for efficient production. During a progressive decline in $\mathrm{O}_{2}$ below the LOS, $S$. aurata gradually reduced their swimming speed, indicative of increasing metabolic stress and/or a 'sit-out' coping strategy which may prolong survival time in severe hypoxia. The feed intake at $12-20^{\circ} \mathrm{C}$ suggests that growth is minimal at the lowest temperature, and that high feeding rates and fast growth can be expected at temperatures $\geq 20^{\circ} \mathrm{C}$. Further studies are required to determine the relationship between temperature, $\mathrm{MO}_{2}$ and LOS for the entire temperature range experienced by $S$. aurata in sea cages, i.e. up to $26^{\circ} \mathrm{C}$.

Acknowledgements. We thank the staff at the Institute of Aquaculture Torre de la Sal (Spain) for rearing of the fish, 
and the staff at IMR Matre (Norway) for management of the experimental facilities and help during sampling. The study was funded by the EU Seventh Framework Programme by the AQUAEXCEL (FP7-2007-2012; grant agreement no. 262336) and the Norwegian Research Council through the Centre for Research-based Innovation in Aquaculture Technology, CREATE.

\section{LITERATURE CITED}

Angilletta MJ Jr, Niewiarowski PH, Navas CA (2002) The evolution of thermal physiology in ectotherms. J Therm Biol 27:249-268

Barnes R, King H, Carter CG (2011) Hypoxia tolerance and oxygen regulation in Atlantic salmon, Salmo salar from a Tasmanian population. Aquaculture 318:397-401

Basurco B, Lovatelli A, García B (2011) Current status of Sparidae aquaculture. In: Pavlidis MA, Mylonas CC (eds) Sparidae-biology and aquaculture of gilthead sea bream and other species. Blackwell Publishing, Chichester, p 1-50

- Behrens JW, Steffensen JF (2007) The effect of hypoxia on behavioural and physiological aspects of lesser sandeel, Ammodytes tobianus (Linneaus, 1785). Mar Biol 150: 1365-1377

> Bejda AJ, Studholme AL, Olla BL (1987) Behavioural responses of red hake, Urophycis chuss, to decreasing concentrations of dissolved oxygen. Environ Biol Fishes 19:261-268

Cech JJ, Crocker CE (2002) Physiology of sturgeon: effects of hypoxia and hypercapnia. J Appl Ichthyol 18:320-324

- Cerezo J, García García B (2004) The effects of oxygen levels on oxygen consumption, survival and ventilatory frequency of sharpsnout sea bream (Diplodus puntazzo Gmelin, 1789) at different conditions of temperature and fish weight. J Appl Ichthyol 20:488-492

Chapman LJ, McKenzie DJ (2009) Behavioural responses and ecological consequences. In: Richards JG, Farrell AP, Brauner CJ (eds) Fish physiology, Vol 27: hypoxia. Elsevier, London, p 26-79

> Claireaux G, Lagardère JP (1999) Influence of temperature, oxygen and salinity on the metabolism of the European sea bass. J Sea Res 42:157-168

> Claireaux G, Webber DM, Lagardère JP, Kerr SR (2000) Influence of water temperature and oxygenation on the aerobic metabolic scope of Atlantic cod (Gadus morhua). J Sea Res 44:257-265

Crampton V, Hølland PM, Bergheim A, Gausen M, Næss A (2003) Oxygen effects on caged salmon. Fish Farming Int June:26-27

> Dalla Via J, van den Thillart G, Cattani O, Cortesi P (1998) Behavioral responses and biochemical correlates in Solea solea to gradual hypoxic exposure. Can J Zool 76: 2108-2113

> Damianidis P, Chintiroglou CC (2000) Structure and functions of polychaetofauna living in Mytilus galloprovincialis assemblages in Thermaikos Gulf (north Aegean Sea). Oceanol Acta 23:323-337

> Domenici P, Steffensen JF, Batty RS (2000) The effect of progressive hypoxia on swimming activity and schooling in Atlantic herring. J Fish Biol 57:1526-1538

FAO (Food and Agriculture Organization of the United Nations) (2013) Fisheries and aquaculture information and statistics service. www.fao.org/figis/servlet/SQServlet?ds=
Aquaculture \&k1=SPECIES\&k1 $=1 \& \mathrm{k} 1 \mathrm{~s}=2384 \&$ outtype $=$ html (accessed on 2 April 2013)

Farrell AP (2009) Environment, antecedents and climate change: lessons from the study of temperature physiology and river migration of salmonids. J Exp Biol 212: 3771-3780

> Feidantsis K, Pörtner HO, Lazou A, Kostoglou B, Michaelidis B (2009) Metabolic and molecular stress responses of the gilthead seabream Sparus aurata during long-term exposure to increasing temperatures. Mar Biol 156:797-809

Fischer P, Rademacher K, Kils U (1992) In situ investigations on the respiration and behaviour of the eelpout Zoarces viviparus under short-term hypoxia. Mar Ecol Prog Ser 88:181-184

Fry FEJ (1947) Effects of the environment on animal activity. University of Toronto Studies Biological Series No 55. Publications of the Ontario Fisheries Research Laboratory No. 68. The University of Toronto Press, Toronto, ON

Fry FEJ (1971) The effect of environmental factors on the physiology of fish. In: Hoar WS, Randall DJ (eds) Fish physiology, Vol 6: environmental relations and behavior. Elsevier, London, p 1-87

Guinea J, Fernandez F (1997) Effect of feeding frequency, feeding level and temperature on energy metabolism in Sparus aurata. Aquaculture 148:125-142

Helland SJ, Grisdale-Helland B, Nerland S (1996) A simple method for the measurement of daily feed intake of groups of fish in tanks. Aquaculture 139:157-163

Hernández JM, Gasca-Leyva E, León CJ, Vergara JM (2003) A growth model for gilthead seabream (Sparus aurata). Ecol Model 165:265-283

Huntingford FA, Kadri S (2008) Welfare and fish. In: Branson EJ (ed) Fish welfare. Fish Veterinary Society, Blackwell, Oxford, p 19-31

Ibarz A, Fernández-Borràs J, Blasco J, Gallardo MA, Sánchez J (2003) Oxygen consumption and feeding rates of gilthead sea bream (Sparus aurata) reveal lack of acclimation to cold. Fish Physiol Biochem 29:313-321

Johansson D, Ruohonen K, Kiessling A, Oppedal F, Stiansen JE, Kelly M, Juell JE (2006) Effect of environmental factors on swimming depth preferences of Atlantic salmon (Salmo salar L.) and temporal and spatial variations in oxygen levels in sea cages at a fjord site. Aquaculture 254:594-605

Johansson D, Juell JE, Oppedal F, Stiansen JE, Ruohonen K (2007) The influence of the pycnocline and cage resistance on current flow, oxygen flux and swimming behaviour of Atlantic salmon (Salmo salar L.) in production cages. Aquaculture 265:271-287

Libralato S, Solidoro C (2008) A bioenergetic growth model for comparing Sparus aurata's feeding experiments. Ecol Model 214:325-337

> Mamun SM, Focken U, Becker KA (2013) Respirometer system to measure critical and recovery oxygen tensions of fish under simulated diurnal fluctuations in dissolved oxygen. Aquacult Int 21:31-44

Metcalfe JD, Butler PJ (1984) Changes in activity and ventilation in response to hypoxia in unrestrained, unoperated dogfish (Scyliorhinus canicula L.). J Exp Biol 108: 411-418

Mingarro M, Vega-Rubin de Celis S, Astola A, Pendon C, Martinez Valdivia M, Perez-Sanchez J (2002) Endocrine mediators of seasonal growth in gilthead sea bream (Sparus aurata): the growth hormone and somatolactin paradigm. Gen Comp Endocrinol 128:102-111 
Mozes N, Papandroulakis N, Vergara JM, Biswas A, Takii K, Ntatsopoulos A (2011) Production systems. In: Pavlidis MA, Mylonas CC (eds) Sparidae-biology and aquaculture of gilthead sea bream and other species. Blackwell Publishing, Chichester, p 169-198

Muggeo VMR (2008) Segmented: an R-package to fit regression models with broken-line relationships. R-News 8:20-25. Available at www.r-project.org/doc/Rnews/ Rnews_2008-1.pdf (accessed on 20 October 2013)

Neill WH, Miller JK, van der Veer HW, Winemiller KO (1994) Ecophysiology of marine fish recruitment: a conceptual framework for understanding interannual variability. Neth J Sea Res 32:135-152

Nilsson GE, Rosen P, Johannson D (1993) Anoxic depression of spontaneous locomotor activity in crucian carp quantified by a computer imaging technique. J Exp Biol 180: 153-162

Oppedal F, Dempster T, Stien L (2011) Environmental drivers of Atlantic salmon behaviour in sea-cages: a review. Aquaculture 311:1-18

Perry SF, Jonz MG, Gilmour KM (2009) Oxygen sensing and the hypoxic ventilatory response. In: Richards JG, Farrell AP, Brauner CJ (eds) Fish physiology, Vol 27: hypoxia. Elsevier, London, p 193-253

Petersen LH, Gamperl AK (2011) Cod (Gadus morhua) cardiorespiratory physiology and hypoxia tolerance following acclimation to low-oxygen conditions. Physiol Biochem Zool 84:18-31

Pörtner HO (2010) Oxygen-and capacity-limitation of thermal tolerance: a matrix for integrating climate-related stressor effects in marine ecosystems. J Exp Biol 213:881-893

Pörtner HO, Grieshaber MK (1993) Critical $\mathrm{PO}_{2}(\mathrm{~s})$ in oxyconforming and oxyregulating animals: gas exchange, metabolic rate, and the mode of energy production. In: Bicudo JEPW (ed) The vertebra gas transport cascade: adaptation to environment and mode for life. CRC Press, Boca Raton, FL, p 330-357

Remen M, Oppedal F, Torgersen T, Imsland AK, Olsen RE (2012) Effects of cyclic environmental hypoxia on physiology and feed intake of post-smolt Atlantic salmon: initial responses and acclimation. Aquaculture 326-329: 148-155

Editorial responsibility: Chris Noble, Tromsø, Norway
Remen M, Oppedal F, Imsland AK, Olsen RE, Torgersen T (2013) Hypoxia tolerance thresholds for post-smolt Atlantic salmon: dependency of temperature and hypoxia acclimation. Aquaculture 416-417:41-47

Richards JG (2009) Metabolic and molecular responses of fish to hypoxia. In: Richards JG, Farrell AP, Brauner CJ (eds) Fish physiology, Vol 27: hypoxia. Elsevier, London, p 444-487

> Richards JG (2011) Physiological, behavioral and biochemical adaptations of intertidal fishes to hypoxia. J Exp Biol 214:191-199

Schurmann H, Steffensen JF (1997) Effects of temperature, hypoxia and activity on the metabolism of juvenile Atlantic cod. J Fish Biol 50:1166-1180

> Secor SM (2009) Specific dynamic action: a review of the postprandial metabolic response. J Comp Physiol B Biochem Syst Environ Physiol 179:1-56

Steinhausen M, Steffensen JF, Andersen NG (2010) The effects of swimming pattern on the energy use of gilthead seabream (Sparus aurata L.). Mar Freshw Behav Physiol 43:227-241

- Svendsen JC, Steffensen JF, Aarestrup K, Frisk M, Etzerodt A, Jyde M (2012) Excess posthypoxic oxygen consumption in rainbow trout (Oncorhynchus mykiss): recovery in normoxia and hypoxia. Can J Zool 90:1-11

Thuy NH, Tien LA, Tuyet PN, Huong DTT, Cong NV (2010) Critical oxygen tension increases during digestion in the perch Perca fluviatilis. J Fish Biol 76:1025-1031

Valverde JC, López FJM, García BG (2006) Oxygen consumption and ventilatory frequency responses to gradual hypoxia in common dentex (Dentex dentex): basis for suitable oxygen level estimations. Aquaculture 256: 542-551

Van Raaij MTM, Pit DSS, Balm PHM, Steffens AB, Van den Thillart G (1996) Behavioral strategy and the physiological stress response in rainbow trout exposed to severe hypoxia. Horm Behav 30:85-92

> Vianen GJ, Van den Thillart GEEJM, Van Kampen M, Van Heel TI, Steffens AB (2001) Plasma lactate and stress hormones in common carp (Cyprinus carpio) and rainbow trout (Oncorhynchus mykiss) during stepwise decreasing oxygen levels. Neth J Zool 51:33-50

Submitted: July 16, 2014; Accepted: June 26, 2015 Proofs received from author(s): August 20, 2015 